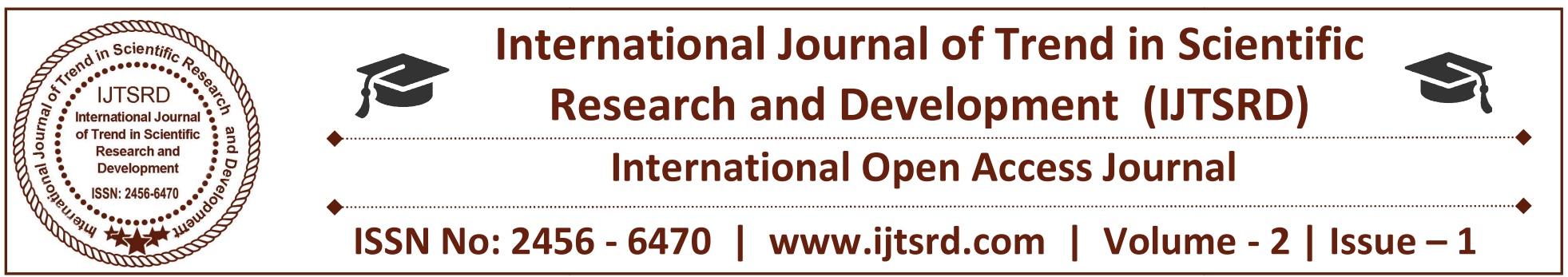

\title{
The Phenomenon of Deconstruction versus the Inherent Desire of Text
}

\author{
Santosh Kumar Nayak \\ Assistant Professor and Head (O.E.S.- A) \\ P.G. Department of Odia Language and Literature \\ Government College, Dayananda Vihar, Koraput, Odisha 764021, India.
}

\begin{abstract}
This study focuses on issues such as what deconstruction is or not, how it is perceived today, what are its benefits, what kinds of mistakes are made in the conception and application as well. The paper tries to unfold the secrets and beauty of the phenomenon of deconstruction from the philosophical approaches to literary discourses. Thus, the techniques of the deconstructive approaches, interactions and interests to the texts have been theorized and the techniques of enforcement have also been given here. Here, attempts have been made to unveil the factual patterns of the phenomenon in order to provide a good understanding to the concept.
\end{abstract}

Keywords: Context, Text, Deconstruction, PostStructuralism

\section{INTRODUCTION}

It is one of the most interesting phenomena encountered in the field of philosophy. The term 'deconstruction' is basically a 'post-structural' phenomenon which deals mainly with the 'context' rather than the 'text'. Jacques Derrida, an Algerian born French phenomenologist, has propounded this concept very carefully with utmost attention. "[...] Deconstruction is the most influential critical movement of the twentieth century. [...] According to Deconstruction, no work of literature whatsoever has been able to express exactly what it wanted to say and thus the critic's business is to deconstruct and recreate them, taking their words as not the outward from of their meaning but only the 'trace of a quest.' [...] The deconstruction philosophy of Derrida is a reaction to the structural anthropology of Claude
Levi-Strauss." (Das, 2014, p. 39) This is such a phenomenon which enhances the probabilities of meanings of the text. It is a channel to uncover the inconsistencies, possibilities, gaps in meaning and mysteries in the consistent structures of philosophical and artistic texts. It is an apparatus for exploring and to critically break down the current pattern and to draw a new one in order to break out new meaning to the context of the society. This is what we understand by Deconstruction and Post-structuralism.

\section{DERRIDA'S THOUGHT ON THE THOUGHTS OF THE TEXT}

Derrida has a number of significant works which pursue the readers' attention in another way. We see the three major and significant works of Derrida for which he established himself as the father of this new thought process in the West. Those books are: Speech and Phenomenon and Other Essays on Husserl's Theory of Signs (La Voix et le Phenomene) (1967), Of Grammatology (De la grammatologie), (1967) and Writing and Difference (L'ecriture et la difference). Of Grammatology, which has been translated by Spivak, is really very important book carrying intense matrix of philosophy. It speaks firmly about the privilege of speech over writing while in Writing and Difference (1967) and Speech and Phenomena he keenly deals with philosophy and language respectively. Here, he has revealed the genetic desire of language and the pattern of meaning within. Now, he has been found significant for his phenomenological debate, i.e. deconstruction. Dissemination(1972), Margins of Philosophy(1972), The Truth in Painting, Of Spirit: Heidegger and the 
Question(1978), The Rhetoric of Drugs, Points, Positions, Acts of Literature(1992), Acts of Religion(2002), Glas(1974), The Postcard: From Socrates to Freud and Beyond(1980), Specters of Marx(1993), The Gift of Death(1995), and Politics of Friendship(1997) are some of his other influential books which disseminate the idea of deconstruction. Besides he has authored many books in French of which some have been translated and some are not yet. Derrida was recompensed an honorary doctorate degree from the Cambridge University. He passed away at the age of 74 in 2004 leaving his conspicuous foot prints on the sand of time. "Derrida's works have dependably had a tendency to very fundamentally political, moral, moral, legitimate, and social issues, making him a key figure in fields outside of the academics. The word deconstruction is gotten from the French verb "deconstuire" connoting to undo the improvement of or the development of, to take to pieces."(Gnanasekaran, 2015, p. 212) We must be very clear that if we need to reconstruct a thing then we must have to deconstruct it first. Hence, this deconstruction is a kind of formality to get a new structure. It is like a death to get a gift of a new life or an escape from the pain and sufferings. Every text/thing/step/voice/vision has another aspect. This is the learning of deconstruction. It never underestimates the future or any possibility but it strictly discards the view of saturation in meaning or to a finite range and domain of meaning of a text.

"Deconstruction is a system that incorporates all other related necessities of building radically and tenaciously, and/ or contains both obliteration and improvement in itself giving space for the Illumination that there is no destruction without advancement and the other way around. As detailed by the French philosopher, the hypothesis is a central critique of certain intellectual and scholarly suppositions that underlie all Western ideas and values. It concentrates on the innate, interior inconsistencies in language and elucidation. The deconstructive hypothesis neither has an idea nor is a type of examination. It is a procedure of deconstructing the text. As indicated by Derrida, in deconstructing the content of the text, the structure is efficiently debilitated so as to be fathomed all the more plainly and to uncover its backings as well as that mystery put in which it is neither development nor destroy but inconvenience or hindrance 'of' or 'for' something. In deconstruction the significance is neither before nor after, or neither inside nor outside of the text. Toward one side, the figural language of writings and expressions of the human experience brings the uncertainty between the genuine and the implied measurements. To put it in other words, the unending bind of signifiers prompts to no conclusion of the text. It is possible only through the chain of signifiers. In fact the chain of signifiers is always the chain of the signifiers but that can never become the absolute signified. Deconstructive examination enrolls a few systems and terms analyze logo centrism which has a tendency to produce or give the last intending to a particular text." (Gnanasekaran, 2015, p. 212)

It rejects the Hegelian concepts of synthesis. Rather it believes in the possibility of synthesis unlike the New Critics. It is a new light on the traditional thought and modus operandi. We can say, it enables, empowers and teaches at the same time to have a new look the same text again and again with the spirit of revolution accepting the trend of evolution at the other hand.

\section{A PROLOGUE TO POST-STRUCTURAL CONCEPT VERSUS DECONSTRUCTION}

With the presentation of Derrida's deconstruction, a new dimension came into being in the field of philosophy and social sciences especially. Derrida's concept of deconstruction came from the opposition to Saussure's structuralism. "Though Derrida criticized Saussure for his meta-physical inclination, he has based his views on those of Saussure, who argued that language signs (words), with their sounds and graphical representations, are arbitrary, and that the meaning of a sign depends on its difference with other signs." (Pati, 2001, p. 128) When one finds a 'signifier' functioning in the text contextually, immediately the reader has to find out the 'signified'. Inna text, a 'sign' never occurs in isolation and it is not the text, but the context which determines the radiations of the sign signifies. Every text, in his perception, is a web of meaning decided by a pattern of structure which could be dismantled at any time as per the desire and potency of the text. He told that language does not destroy a text but just deconstructs it. The term 'deconstruction' has been derived from the term 'destroktion' used by Martin Heidegger in Section VI of 'Being and Time'. It is the most controversial concept of the sixties and onwards. "Derrida's initial and decisive strategy is to disestablish the priority, in traditional views of language, of speech over writing. By priority I mean 
the use of oral discourse as the conceptual model from which to derive the semantic and other features of written language and of language in general."(Abrams, 2004, p. 244) A violent intervention is required in the system of language. Languages are man-made. Hence, they are just like human beings: incomplete and impotent to express all they feel. Again, peculiarly they are sometimes ambiguous and therefore create confusion. "[...] deconstruction aims at liberating language from the traditional western concept and to make a fresh concept of text along with ways of dealing with it. It is in this regard that Derrida proposes 'dissemination' as an alternative to the polysemy of interpretation. In contrast to interpretation, which is sterile product, dissemination is a fertile process, a proliferation of signs or seeds that regress to infinity- to a truth that exists only at a purely hypothetical vanishing point where parallel lines of signifier and signified presumably meet. Derrida argues that there exists no signified that transcends the text (or series of signifiers), no signified that in imagination, intention, or experience thematizes what the text means with the result that the text ceases to express or represent any polysemous truth. Deconstruction rejects all earlier methods of criticism and supplies no single method." (Das, 2014, p. 47) It empowers the critic to overtake the author, but it is also at the same time, silent about the inherent desire of the text. The source of the desire of the text of course is not the author. An author is just a medium to transmit the philosophy, who acts as a conductor of course. At the same time, if the critic or a reader holds the other meaning of the text, it implies that $\mathrm{s} / \mathrm{he}$ is also associated with the perennial source of the meaning or the particular pattern or the context or you say the desire of the text.

However we must talk about the Yale scholar group while discussing the phenomenon of deconstruction. It is really a significant group of scholars who were not only challenging by mind but adventurous by spirit also, which brought a potential revolution in the world of humanities and social sciences.

"The Yale scholars were firmly connected to the theory of deconstruction. Deconstruction mainly concentrates on the inconsistencies in language and interpretations. This area presents poststructuralism, its development and significance in the zone of literary and cultural studies, and the idea of deconstruction.[...] Post-structuralism is a movement in social sciences that developed in France in the late 1960s. It is the result of both the structuralist period of examining sign and structure, and the humanist paradigm of concentrating on the texts, the writers, the readers, and histories. Jacques Derrida gave the essential establishing to the hypothesis of deconstruction with his address Structure, Sign and Play in the Discourse of the Human Sciences in 1966. In light of this, different post-structuralists propounded their hypotheses. For instance Jacques Lacan for psychoanalysis, Michel Foucault in philosophy, Roland Barthes in semiotics, Julia Kristeva in social criticism, Jean-Francois Lyotard in political hypothesis, and Jacques Derrida with his deconstruction hypothesis' are the most 'praised experts' of the development." (Gnanasekaran, 2015, p. 212)

Deconstruction is not a method simply; rather it is an exorbitant method. This concept has been imported from John Caputo. The concept states that the exorbitance presupposes an orbit to displace. We find here a 'return' in any turn in an orbit. We search for a new and valid meaning in this process. An imagery of an orbit is found in Derrida's phenomenon. We can rightly recall his statement that everything is text and nothing is there outside of the text.

\section{DECONSTRUCTION: ITS SCOPES AND FUNCTIONS}

With reference to the situation, class, reader etcetera the same text gets multiple numbers of meanings. In order to unveil the secrets contained in a particular text, he says: "I have never claimed to identify myself with what may be designated by this name. It has always seemed strange to me, it has always left me cold. Moreover, I have never stopped having doubts about the very identity of what is referred to by such a nick-name."(Derrida, 1995, p. 15) Interestingly, Derrida says about the concept of deconstruction in his 'Letter to a Japanese Friend': "What deconstruction is not? Everything of course! What is deconstruction? Nothing of course!" (Derrida, 1991, p. 275) What a beautiful and worth answer is it! In fact, this is the most apt answer Derrida could ever have given in this context. Regarding its nature and scope we can again quote his statement which would not only be relevant but also the most correct expression in this regard, even better than any other's expression. "[...] deconstruction doesn't consist in a set of theorems, axioms, tools, rules, techniques, methods...there is no deconstruction, deconstruction has no specific object...(Derrida, 1996, p. 218) It is 
not that like any other theory on the basis of the perceptions of which a particular text or any kind of text is to be treated. It has only one rule for the readers and that is having no specific rule to follow. He further clarifies his concept of treatment to the texts and says-

"[...] deconstruction is neither an analysis nor a critique. ...I would say the same about method. Deconstruction is not a method and cannot be transformed into one. ...It must also be made clear that deconstruction is not even an act or an operation..." (Derrida, 1991, p. 273)

It has only one commitment that anything is possible in a text with reference to the context by a reader. Therefore he says, "[...] deconstruction loses nothing from admitting that it is impossible."(Derrida, 1991, p. 272) Many of the critics adopt the phenomenon as it is. It is, in other words, the immense possibilities or the potencies contained in a text.

"Deconstruction is nothing, it is not a method, not a technique, not even an act, because a 'deconstructive reading attends to the deconstructive processes always occurring in the texts and already there waiting to be read" (Payne, 1993, p. 121).

For instance, the 'plants' should not be called as plants, trees etcetera. What does it mean? They should rather be called as 'energy-binders', 'producers' etcetera. Meaning is always personal, not general. Again, words don't have any specific meaning because nothing is absolute, nothing is statutory or final. Hence, medium is the message. It is the language which acts as a medium. And it is equally true that the languages have some limitations like the human beings. Perhaps that's why Joshua Whatmough had told aptly in his famous book 'Language', 'language is human... a verbal systematic symbolism... a means of transmitting information... a form of social behavior with high degree of communication" (Sahu, 2005, p.11) which was rightly quoted by Professor Basudeva Sahu. Language is simply a representative which cannot express the total or all meanings at once. We can recall the words of Max Muller: "Myth is the maladydisease of language." Here, we ensure how a word gets a new meaning according to its inherent desires at its unconscious level. Hence, language is an insufficient and faulty system itself. Language precedes interpretation and vice versa. So far the meaning concerns, "[...]; it is already there, it is the tension 'between what [the text] manifestly means to say and what it is nonetheless constrained to mean' (Norris, 1987, p. 19).

To acknowledge the above said matter and of course in order to define it, says Payne, it is "the impossible desire of language..." (1993, p. 121). The texts deconstruct themselves as they get attached to the proper catalysts like environment or you say that to a reader of different introspections and typical perspectives. Hence, many critics of this area designate language of any text as a 'transcendental signifier' (Usher \& Edwards, 1994) which is quite logical. G.C. Spivak (1976) very interestingly finds the peculiar behavior of a text in her keen observation and rightly says over that, "All texts...are rehearsing their grammatological structure, self-deconstructing as they constitute themselves" (p. 1xxviii). Barthes (1970) has written a very significant thing in this respect. He says, "to write is an intransitive verb" where everything is concerned here with writing, according to him no specific objective or goal or conception should be there. We know "deconstruction manifests itself in the process of writing rather than in the product" (Rolfe: 2004, p. 274). Being more particular, we can equalize the process just with the fast organic reactions (a chain/series of reactions) of carbon and chlorine in the presence of sunlight. 'Deconstruction takes place, it is an event that does not await the deliberation, consciousness, or organization of a subject' (Derrida, 1991, p. 274). "But if this is indeed the case, then deconstruction is impossible in another and more tangible sense. Firstly, the process of deconstructive writing produces a second text as a supplement to that which it seeks to deconstruct, which is itself (in Spivak's words) self-deconstructing as it constitutes itself. Secondly, there is no single authoritative and 'correct' deconstructive reading/writing of any particular text. Therefore, each text contains within itself the possibility of a vast number of supplementary deconstructive texts, and each of those is likewise open to further deconstruction ad infinitum in an infinite regress." (Rolfe, 2004, p.274) Spivak (1976) says that "We are intoxicated with the prospect of never hitting bottom" (p. 1xxvii) as it has both the capacity to render fear as well as pleasure. Many of the critics remain in puzzle with the proper meaning or implication of deconstruction. We can notice the remarks of McQuillan in this regard to get a clear picture of the concept. McQuillan encounters the 
etymological sketches of the phenomenal term and its background as well. He emphasizes on the term 'pas de méthode', which is very significant itself. From this source, encountering Derrida's assertion that deconstruction is not a method ('pas de méthode') which can itself be deconstructed, says McQuillan"The word pas in French means both 'not' and 'step', so this ambiguous phrase can be translated as either "not a method" or "a methodological step" " (McQuillan, 2000, p. 5). How accurately and dexterously the things have been told! It is not a method; rather it is a methodological step. That's why Derrida has rightly told that it is not a method, not even a theorem or any axiom. It is just a phenomenon.

\section{THE PHENOMENA WITHIN THE PHENOMENON}

A text is constituted of multiple numbers of circles multi-dimensionally. Some are visible and some are not. Hence, a text has a number of centres which move the context or the meaning of the text. Even, meaning changes depending upon the primary, secondary and tertiary aspects of assets like reader, society, environment, and time etcetera. Similarly, if we notice vividly, we can firmly draw the conclusion that- "It is an apparatus or an ordinance by which one endeavours to comprehend a literature. One can decipher and evaluate a literature on the premise of theories. It is theories that help the readers in analysing the relationship between the creator and the work. Several critics frequently give the estimation of a specific literature taking into account scholarly ordinances, tools and hypotheses and mention judgments through objective fact as a piece of literary criticism. This area clarifies the part of a deconstructionist and his role in examining the text. A deconstructionist participates in the assignment of recognizing the unconscious measurement of the text, instead of the cognizant or conscious measurement. Derrida considers the text to be the subject and object of investigation." (Gnanasekaran, 2015, p. 212) He further adds, "Verbal signs, parallel contrary energies, word play, metaphors, allegories, allusions and implications found in the selected text make reading and deciphering entangled to the deconstructionist. The deconstructionist embarks to demonstrate that clashing powers inside of the particular itself serve to scatter the appearing definiteness of its structure and implications into an inconclusive exhibit of contradictory and undecidable possibilities." (2015, p. 2012) A text does no permanent agreement with any sorts of meaning. If it does any kind of agreement or pact or deal then it is for a temporary period though not specific. It breaks the contract at time with the previous meaning and make a new one with regard to the particular situation and necessarily. Again, it is equally true that the components of the text move in the air or they remain in the environment in different form in different places. During the need, that is, during the desire of the text they come into the physical text and the reader finds that at that time. Then only s/he interprets that particular text something differently. We can tell those mini text parts as textules or text-lets. And these text-lets in fact decide the direction of meaning of a particular text. We name this phenomenon- the different interpretation of the text by the reader. And here, the invisible circles become visible gradually by the result of which a new centre is located which of course disseminates and imparts the meaning which is not only new but also different from the early one disseminated by another circle. "This implies that the content may be a composite of different inside inconsistencies, discontinuities, and irregularities. Inner disagreements may be as paradoxes; discontinuities as crevices, gap, tense, time, individual, or state of mind; and irregularities in pluridimensional." (Gnanasekaran, 2015, p. 212-13)

"The deconstructionist accepts four parts. He is now and again a reader of the text, a decipherer, an investigator, and at some different times, a correct critic. The deconstructive reader is an eyewitness who is materially outside the content, however purposefully included inside of the text. He always moves and receives his position to the differing points found in the text and goes to an agreement of the significance inferred or determined. Derrida's depiction of deconstructive perusing is that the deconstructionist as a reader must go for a certain relationship, unperceived by the author, between what he orders and what he doesn't charge of the structures of language that he utilizes. That is, the reader of the text recognizes certain crevices or blanks or blind spots and tops them off by bringing the different social, memorable, and social standards applicable to the content before deciphering the text. He unites the language of the text, history, the idea of structure and phenomena of style. In this try, he derives a few deconstructive components while understanding and deciphering literary texts."(Gnanasekaran, 2015, p. 213)

That means in this process the major shareholder of a text is reader, not the writer. We need not say the 
theory of Barth in this regard. S/he has to dismantle the pattern of the text first of all. In this way a reader has to be conscious enough of the structure, which alludes to space, geometric or morphological space, of the pattern underlined in the text, the inside solidarity of a cluster etcetera in order to dismantle it $\mathrm{S} /$ he should be careful to the verbal as well as the semantic system of the text. Here s/he can use any kind of device in order to reveal the desire of the text, i.e. the other meaning which is of course not final. The reader or the critic needs to examine the opposing components(binary opposites) or the paradoxical patterns or contradictory connections in the textual content until they achieve an aporia. "As a critic or a reader, the deconstructionist comprehends that significance of the text is vast." (Gnanasekaran, 2015, p. 213) But I differ from this view. These critics pay much more importance and attention to the readers and to their philosophy, societal background, and cultural base etcetera. The target of the reader, here, is to deconstruct the content of the text. The reader looks into the sequences of language and tries to unveil the meaning or the underlined meaning. The interpreter is required just to deconstruct the text. This proves the double edged tendency of word which ultimately brings a new light in the context of that text without recreating or rewriting it. So a deconstructionist need not recreate, rebuild, reconstruct the content of the text. S/he only has to re-read the content (text) in order to examine its each and every entry which leads her/him to recognize the inside inconsistency, discontinuities, and irregularities. "The deconstructionist fixes the surface components of words and conveys them to the front area founding up their significance or need in the general play of work of art."(Gnanasekaran, 2015, p. 213) Just like a human being, a text has its conscious, sub-conscious and unconscious mind. With reference and regard to the time-space and person it goes for the different states and strata of its consciousness. This how, the meaning generates. In fact, the meaning was there from the very first. But it was invisible due to its dormant state in the unfavorable/hostile environment (hostile for a particular thought or meaning which is/are yet to come). With favorable environment the meanings came out as per the theory of Doctor Sigmund Freud. Overall, a deconstructionist researcher accepts all the functions of being a reader, an interpreter, an examiner, an investigator, an evaluator and a critic, at different points. This why, $\mathrm{s} /$ he is the major share-holder and the actual owner of the text.
Deconstruction cannot be tied down to a single meaning as Derrida says. Deconstruction is a journey, a continuous expedition but an object. It is a free state of reading and rewriting a text. No retarder or accelerator of any action or reaction of the previous concepts should bias the reader while s/he is being treated with this phenomenon. In fact, a reader reads as simply and as naturally he s/he can. The phenomenon occurs itself. No protocol should be there. While some say that it is not a system but an ensemble of rules or patterns for reading, interpreting and writing. Spivak, in a revealing temperament, provides a few clues in her 'Translator's Preface' to Of Grammatology in this regard and says: "To locate the promising marginal text, to disclose the undecidable moment, to pry it loose with the positive lever of the signifier; to reverse the resident hierarchy, only to displace it; to dismantle in order to reconstitute what is always already inscribed. Deconstruction in a nutshell." (Spivak, 1976, p. lxxvii)

Gary Rolfe has deeply studied the phenomenon and thereafter he dictates the methods of dismantling a text with the following strategies. To dismantle a particular text in order to reconstitute or reorganize what has already been described or organized in a particular pattern with reference to certain circumstances and circumference, we can discern three crystal clear and conspicuous strategies by which such a dismantling operation might be accomplished. These strategies are really significant and useful during the operation of deconstruction.

\section{To locate the promising marginal text,} (Rolfe,2004, p. 275) i.e., to write of, in and at the margins, "seizing on precisely those unregarded details (casual metaphors, foot notes, incidental turns of argument) which are always and necessarily, passed over by interpreters of a more orthodox persuasion" (Norris, 1987, p. 19). The text should be well caught and made out.

To disclose the undecidable moment, to pry it loose with the positive lever of the signifier, (Rolfe, 2004,p. 275) that means, to expose the possibilities and the desires of the text by the practice of double coding (or 'double-edged words' as named by Spivak) in order to demonstrate the antithesis which is already and always present in every thesis. Because every text has it different interpretations with regard and reference to the different mind, place and time. In 
a present context or with reference to a certain time, mind or place all the possibilities and dimensions of meaning cannot be unveiled at a time. It that particular time which will unfold and unveil the other truth with that.

To reverse the resident hierarchy, only to displace it, (Rolfe' 2004, p.275) that implies, to expose, dismantle and to challenge the binary opposites in the text, to expose the unacknowledged (and perhaps unconscious) taken-for-granted power hierarchies within the text, to reverse them, and finally to pull them apart. By changing the order of the 'subtexts' or the 'text-lets' (or we may name them 'textules') we can simply dismantle the text and dislocate the centre of meaning.

Bennington has rightly told the crux matter of deconstruction with his prompt words in this order'Deconstruction is not what you think' (Bennington, 1988 , p. 6). Interestingly, the real meaning of the phenomenon lies here, which could be entitled as the bottom line, the degree zero, of deconstruction. We can have the lines of Norris right here in this regard. "Deconstruction is the active antithesis of everything that criticism ought to be if one accepts its traditional values and concepts' (Norris, 1991, p. xi). "Criticism traditionally seeks to establish the authorized meaning of the text, the original meaning placed in the text by the author." (Rolfe, 2004, p 275) But here I differ from this view. There is no original meaning of a text, first of all, as the complete meaning of a text will only be possible out of the summation of the meanings of the reader(s) and the author(s). It is the meaning of the text that lies not in it but elsewhere beyond its visible range and domain. This is the sole cause of deconstruction phenomenon. This, on face creates chance(s) or various possibilities of a particular text. This is the way deconstruction consists in putting this authority 'out of joint' (Derrida, 1995, p. 25).

\section{CONCLUSION}

Deconstruction is not only the enemy of the authorized/authoritarian texts but a revolution as per the need of the hour which has been from the early days till today. Deconstruction is only due to the inherent desire of the text. Again, that desire is based on the quest or the search of reader with no specific objective. It is the go of the text to be found out by the reader without any go. It is the most interesting deal in this typical phenomenon.

\section{REFERENCES AND WORKS CITED}

1) Abrams, M. H. (2004). 'The Deconstructive Angel'. In: Modern Criticism and Theory: A Reader. (ed. David Lodge \& Nigel Wood ) Pearson Education: Singapore.

2) Barthes R. (1970) To write: an intransitive verb. In: The Language of Criticism and the Sciences of Man (eds R. Macksey \& E. Donato), pp. 134-145. Johns Hopkins University Press, Baltimore, MD.

3) Bennington G. (1988) Deconstruction is not what you think. Art and Design, 4(3/4), 6-7.

4) Das, B.K. (2014) Twentieth Century Literary Criticism. Atlantic Publishers and Distributers (P) Ltd., New Delhi

5) Derrida J. (1991) Letter to a Japanese friend. In: $A$ Derrida Reader (ed. P. Kamuf), pp. 270-276. Harvester, New York, NY.

6) Derrida J. (1995) The time is out of joint. In: Deconstruction Is/in America: A New Sense of the Political (ed. A. Haverkamp), pp. 14-41. New York University Press, New York, NY.

7) Derrida J. (1996) 'As if I were Dead': an interview with Jacques Derrida. In: Applying: To Derrida (eds J. Brannigan, R. Robbins \& J. Wolfreys), pp. 212-227. Macmillan, London.

8) Gnanasekaran R (2015). An Introduction to Derrida, Deconstruction and Post- Structuralism. Inter. J. Eng. Lit. Cult. 3(7): 211-214.

9) McQuillan M. (2000) Introduction: five strategies for deconstruction. In: Deconstruction: A Reader (ed. M. McQuillan), pp. 1-43. Edinburgh University Press, Edinburgh.

10) Norris C. (1987) Derrida. Fontana, London.

11) Norris C. (1991) Deconstruction Theory and Practice. Routledge, London.

12) Pati, P.K. (2001) The Evolution of Literary Criticism. Snehalata Press, Salem, Oregon, USA.

13) Payne M. (1993) Reading Theory. Blackwell, Oxford.

14) Rolfe, G. (2004) 'Deconstruction in a Nutshell'. In: Nursing Philosophy 5. Blackwell Publishing Ltd ., pp. 274-276.

15) Sahu, B. (2005) Bhashabijnanara Ruparekha (An Outline of Philology). Friends' Publishers, Cuttack.

16) Spivak G.C. (1976) Translator's preface. In: $O f$ Grammatology (ed. J. Derrida), pp. ix-lxxxvii. The Johns Hopkins University Press, Baltimore, MD.

17) Usher R. \& Edwards R. (1994) Postmodernism and Education. Routledge, London. 